Kulturen und Werte 


\section{Über Wittgenstein}

Herausgegeben im Auftrag der

Internationalen Ludwig Wittgenstein Gesellschaft e.V. von James Conant, Wolfgang Kienzler, Stefan Majetschak, Volker Munz, Josef G.F. Rothhaupt, David Stern und Wilhelm Vossenkuhl

\section{Band 1}




\section{Kulturen und Werte}

Wittgensteins KRINGEL-BUCH als Initialtext

Herausgegeben von Josef G. F. Rothhaupt und Wilhelm Vossenkuhl

\section{DE GRUYTER}


ISBN 978-3-11-027749-4

e-ISBN 978-3-11-027756-2

\section{Library of Congress Cataloging-in-Publication Data}

A CIP catalog record for this book has been applied for at the Library of Congress.

\section{Bibliografische Information der Deutschen Nationalbibliothek}

Die Deutsche Nationalbibliothek verzeichnet diese Publikation in der Deutschen Nationalbibliografie; detaillierte bibliografische Daten sind im Internet über http://dnb.dnb.de abrufbar.

(C) 2013 Walter de Gruyter GmbH, Berlin/Boston

Satz: Medien Profis GmbH, Leipzig

Druck und Bindung: Hubert \& Co. GmbH \& Co. KG, Göttingen

@ Gedruckt auf säurefreiem Papier

Printed in Germany

www.degruyter.com 